\title{
Low-Cost and Portable Ground Station for the Reception of NOAA Satellite Images
}

\author{
Antony E. Quiroz-Olivares ${ }^{1}$, Ntalia I. Vargas-Cuentas ${ }^{2}$, Guillermo W. Zarate Segura ${ }^{3}$, Avid Roman-Gonzalez ${ }^{4}$ \\ Image Processing Research Laboratory (INTI-Lab), Universidad de Ciencias y Humanidades, Lima, Peru
}

\begin{abstract}
Currently, in Peru, the study of satellite images is increasing because it has the Earth observation satellite PeruSat1. However, the cost of implementing a ground station is very high; for this reason, it is baffling that each university has its station. In the present work, the design and implementation of a low-cost portable earth station for the reception of meteorological satellite images is proposed in an automatic way, using accessible electronic devices such as Raspberry $\mathbf{P i} \mathbf{3 b}+$, Software Defined by Radio (SDR) and an antenna double cross four dipoles, in this way encourage the study of satellite images in schools and universities. The results obtained show the viability of this project.
\end{abstract}

Keywords-Software defined by radio; Raspberry Pi; meteorological images; antenna; dipoles

\section{INTRODUCTION}

In Peru, the study of satellite images is in advance with the National Centre for Operations of Satellite Images (CNOIS for its Spanish acronym) that provides the images from the PeruSat-1 Earth Observation Satellite to different public and private entities. Every image distribution takes in to account the security and national interests. CNOIS belong to the Peruvian Space Agency (CONIDA for its Spanish acronym for National Commission of the Aerospace Research and Development National Commission). CONIDA promotes the development, research, and dissemination of space science and technology, contributing to the socio-economic development of the nation. The cost of the ground station for the PeruSat-1 was more or less $\$ 9.7$ million. For the use of these satellite images, the interested entities must assign two employees as representatives of the institution, who have to manage the request and reception of CNOIS products. The reception of these images is carried out by a direct link from the ground station to the PeruSat-1 [1].

The PeruSat-1 is an Earth observation satellite acquired by the Peruvian government. It is used for multiple productive sectors as the mining sector, agricultural, civil defense, environmental, among others [2].

Regarding Earth observation satellite, there are also meteorological satellites that are in charge of supervising the atmospheric time and the displacement of the clouds around the world [3].

Meteorological satellites are separated into two types, those of fixed observation of territory that is the geostationary orbit and those that observe throughout the world in a day, they have a polar orbit and are free use [4].
Since 1978 the National Oceanic and Atmospheric Administration (NOAA) together with the National Aeronautics and Space Administration (NASA) of the United States have built a series of Environmental Satellites in Polar Orbit (POES), these satellites transmit images of the terrestrial or marine and atmospheric surface captured by their sensors in real time. Sending these measurements for climate modeling around the world used to anticipate natural disasters and weather conditions 3-7 days before they occur [6] [7].

The POES satellites transmit two types of images in real time, one by a direct link in the S-band, which is the HighResolution Picture Transmission (HRPT) and the other by the VHF band which is the Automatic Picture Transmission (APT). Images from APT are the third part of the resolution of the HRPT; one currently has three satellites that transmit in APT, these are NOAA15, NOAA18 and NOAA19. The transmission of these images is given by the frequency of 137 $\mathrm{MHz}$ [4].

Currently, there are raspberry pi based systems for the reception of NOAA APT images, one of these systems is used manually as users who use it have to be present when passing NOAA satellites [5].

Currently, the implementation of a ground station for the reception of satellite images comes very expensive and in turn needs to have qualified personnel for its management, for this reason, universities do not have a ground station for the reception of satellite images.

In the present work, one proposes to implement a portable and low-cost system (approximately 120 dollars of investment), for obtaining meteorological satellite images - of APT type - automatically. The idea is to facilitate to users in the handling of a portable ground station, motivating to the study of the climatic patterns of its locality. For it, one will use a raspberry pi b+, a Software Defined Radio (SDR) and an arrangement of a double cross antenna with which we will receive the signal APT to later decode it and to store it in the computer for its later study.

In Section II, one describes the steps for the ground station implementation. Section III shows the obtained results. Section IV describes the discussion and the future perspectives of our ground station.

\section{METHODOLOGY}

The operation of the proposed system can be seen in the following block diagram in Fig. 1. 


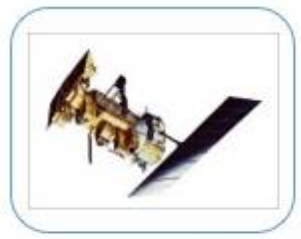

SATELLITE

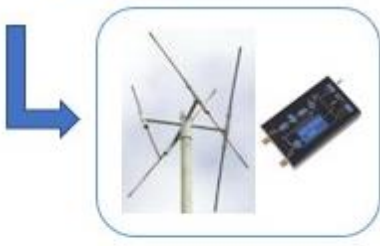

COMMUNICATION

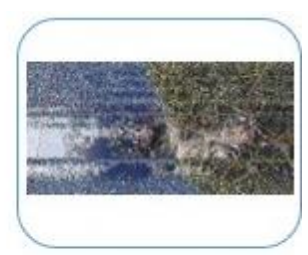

VISUALIZATION
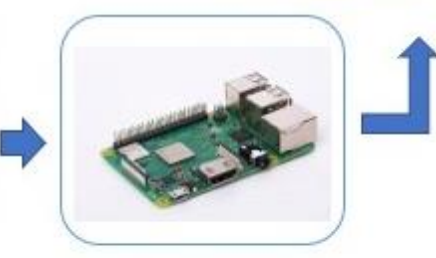

CONTROL
Fig. 1. Block Diagram of the Proposed System.

\section{A. Space Segment}

The space segment is composed by the NOAA weather satellites. These satellites capture real-time images of the place where they pass and transmit it in HRPT and/or APT format [4].

\section{B. Communication Module}

The system receives APT satellite images thanks to the double cross antenna of four dipoles Fig. 2, the design of the antenna is ideal for the reception of this type of signal; in addition, its components for its construction can be acquired in any hardware store [8].

Software Defined Radio (SDR) is responsible for tuning the frequency of the NOAA satellite signal; in Fig. 3 one see the SDR that controls all its physical functions by software [9], this device is used for educational purposes, as it is a low-cost system that can help understand the functioning of real communications.

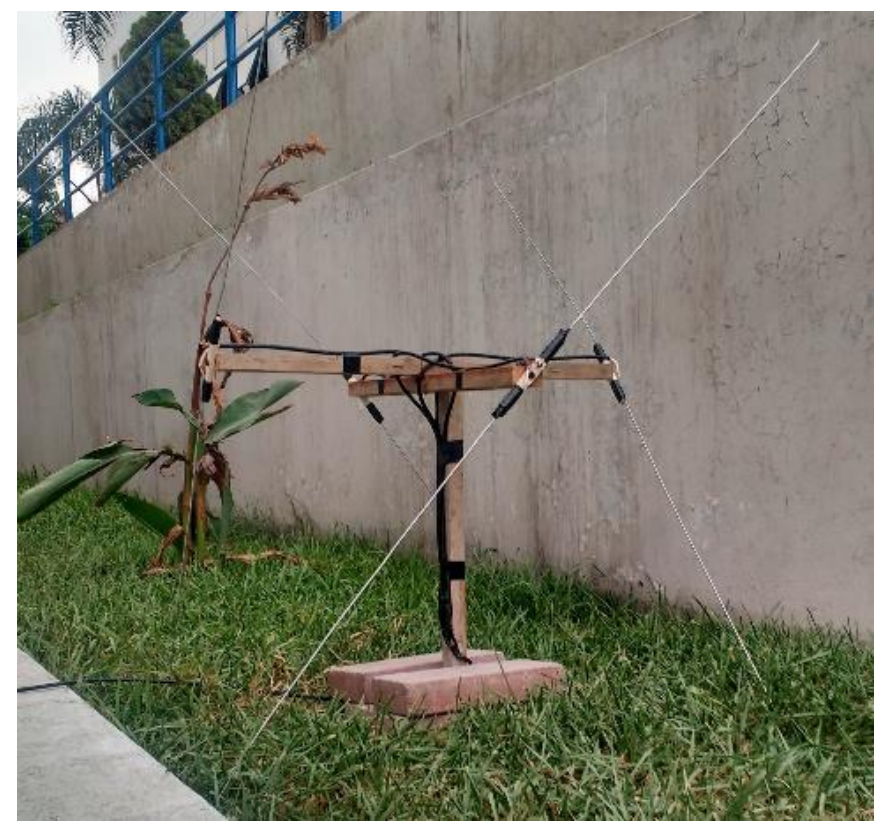

Fig. 2. Double Cross Antenna.

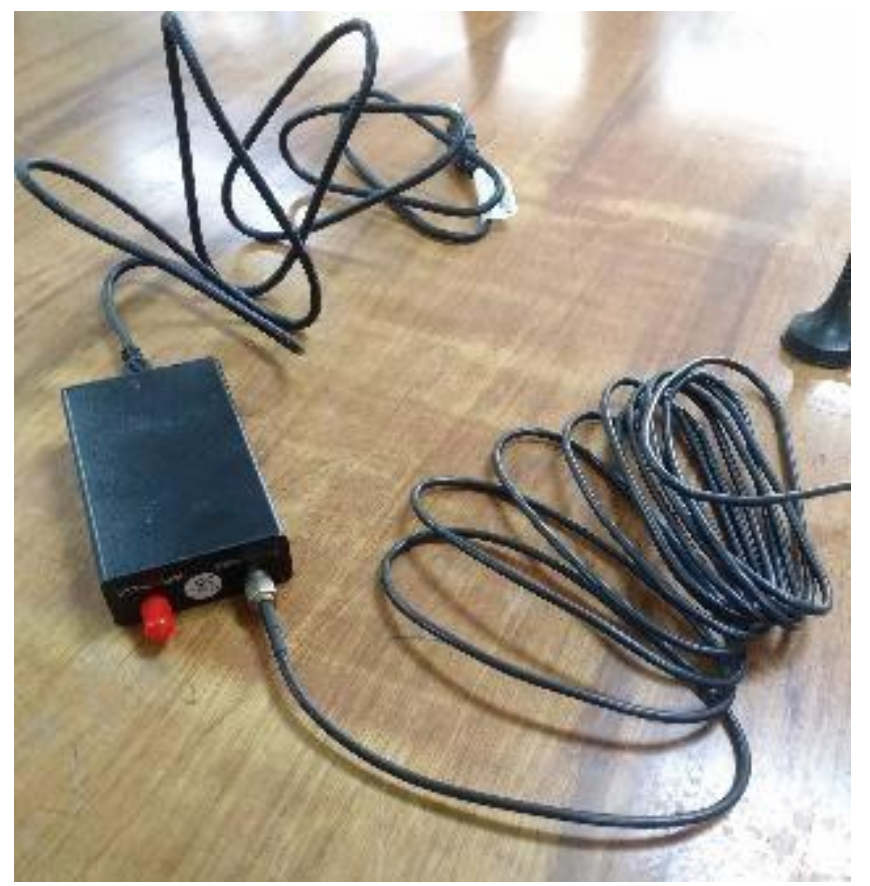

Fig. 3. Software-Defined Radio.

\section{Control Module}

The raspberry $3 b+$ Fig. 4 , is responsible for controlling the SDR for the reception of satellite images, this is affordable minicomputer capable of running the applications needed for the portable and automatic ground station. Compared to previous versions, the raspberry $3 \mathrm{~b}+$ has increased in processing speed from $1.2 \mathrm{GHz}$ to $1.4 \mathrm{GHz}$, also improved wireless connectivity, now works in dual band $2.4 \mathrm{GHz}$ and 5 $\mathrm{GHz}[10]$.

\section{Display Module}

For the visualization of the received images, it is necessary the installation of the following applications:

1) Raspbian: The Raspbian is an operating system based on Linux oriented to computers with few hardware resources such as the raspberry [11], in Fig. 5 one see the graphical environment of the Raspbian operating system.

2) RTL-SDR: It is an application that is responsible for the control of SDR, such as the frequency at which it must be tuned and the bandwidth needed to receive the information [12]. Table I shows the frequencies at which NOAA satellites transmit information.

3) SOX: It is a set of audio tools that allow us to manage the flow of received audio. This tool will enable us to record and store the audio captured by the SDR [13].

4) Predict: It is an open source program that provides satellite positioning in real time ${ }^{1}$, the use of this application is only by console, unlike another similar program, the prediction does not need so much hardware resource, so it is perfect for this type of projects. In Fig. 6 one visualizes the initial configuration. 


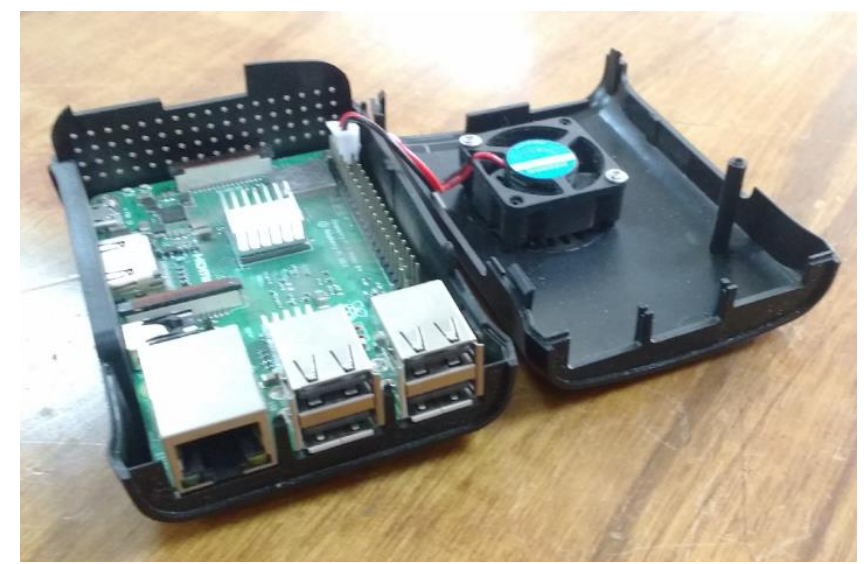

Fig. 4. Raspberry pi 3b+.

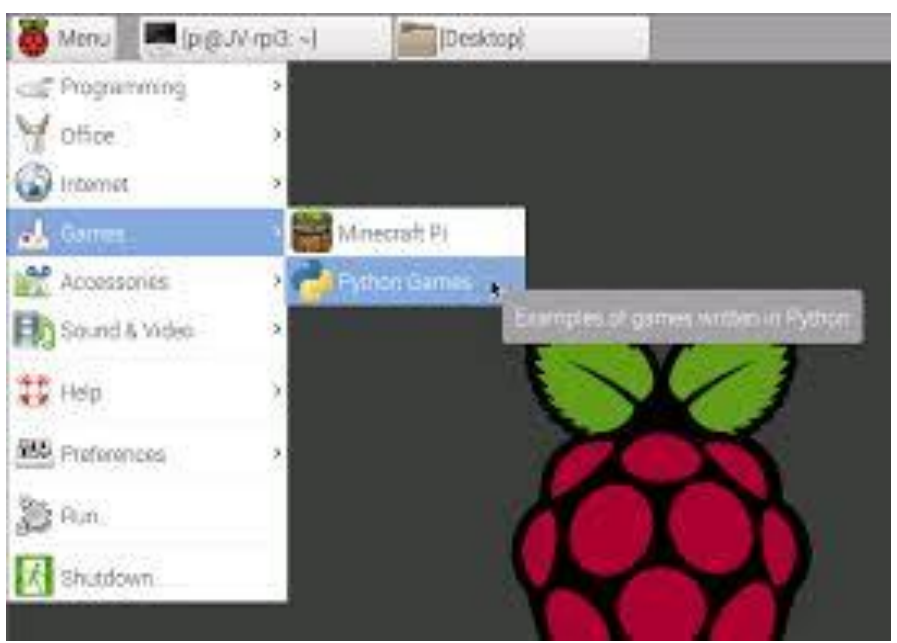

Fig. 5. Graphical Environment of the Raspbian Operating System.

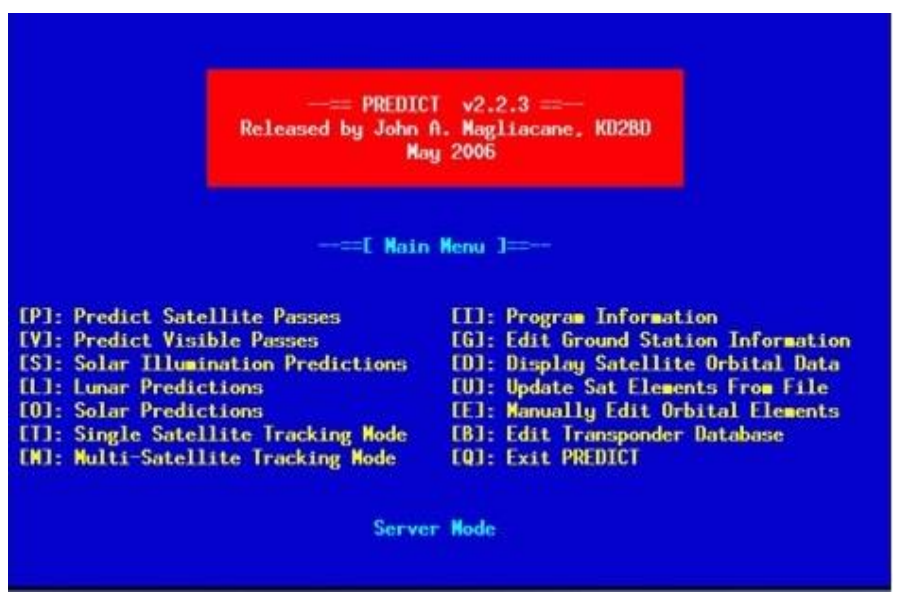

Fig. 6. Initial Configuration of the Predict Application.

TABLE I. FREQUENCIES OF NOAA SATELLITES

\begin{tabular}{|l|l|l|}
\hline Satellite & Receiving frequency $(\mathbf{M H z})$ & Wavelength $(\mathbf{m})$ \\
\hline NOAA 15 & 137.620 & 2.18 \\
\hline NOAA 18 & 137.9125 & 2.175 \\
\hline NOAA 19 & 137.100 & 2.188 \\
\hline
\end{tabular}

5) WXtoimg Restored: It is a decoder of meteorological satellites, that allows us the edition and visualization of the received images in the form of audio, between its main features one can mention that it is possible to work with command lines to execute it automatically in the second plane ${ }^{2}$. In Fig. 7 one visualizes the graphical environment of the WXtoImg, this way of using the application is decided by the user.

\section{E. Execution Process}

One installs the SDR USB drivers, then install the RTLSDR application along with the SOX audio tools. To locate the satellites, one installs the Prediction program, where we have to place the coordinates where the portable ground station will be located, and finally one install WXtoimg restored, this program will be in charge of decoding the captured audio and converting it into a satellite image. With the applications already installed one proceed to create the scripts that will be responsible for doing the whole process automatically. The automatic system starts at midnight downloading a list of satellites that will pass during the day; the Predict application provides this information.

With the list of satellites NOAA15, NOAA18 and NOAA19 already programmed, the script calculates the time in which each satellite will pass in the day.

The script programs of the RTL-SDR as well as of the SOX will be executed in a precise instant that the satellite passes through our location.

The system will start tuning to the $137 \mathrm{MHz}$ frequency, beginning the recording of an audio file until the satellite is over.

After passing the satellite, the WXtoimg restored application will run, decoding the recorded audio file and converting it into an image, saving it in a raspberry pi b+ folder as shown in Fig. 8.

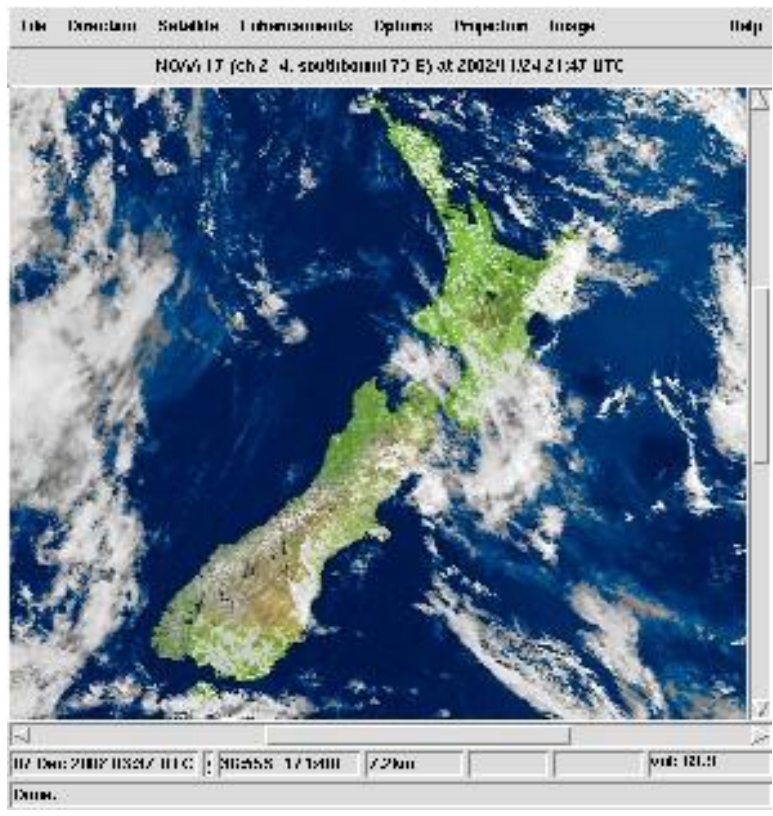

Fig. 7. WXtoImg Application. 

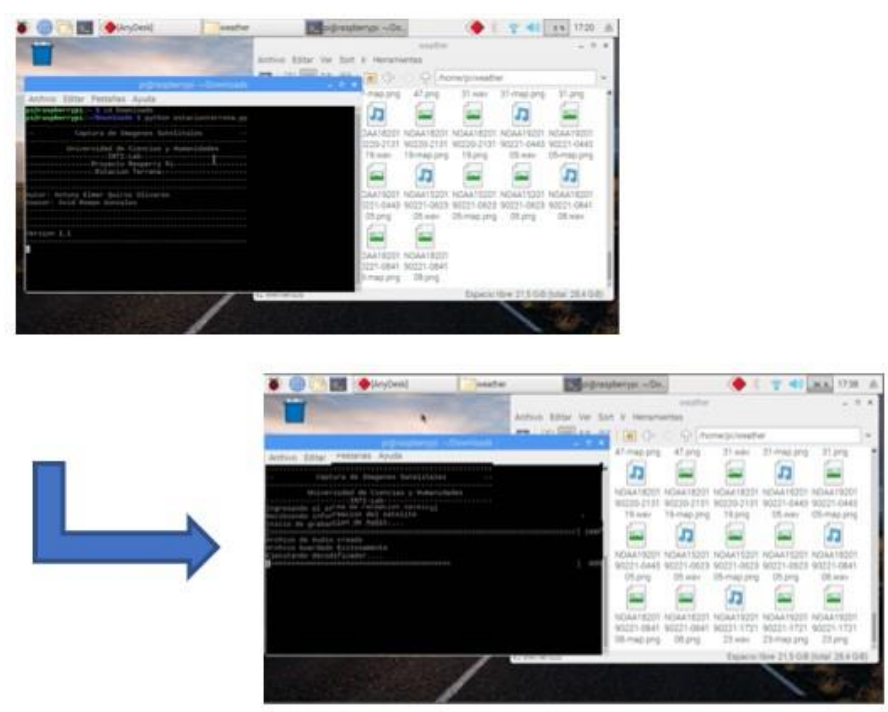

Fig. 8. Creation of Audio Files.

As soon as the NOAA satellite passes through our location, it sends the APT signal to Earth.

The four-dipole double-cross antenna receives the electromagnetic wave from the satellite and converts it into an electrical signal.

Software Defined Radio (SDR) demodulates the electrical signal from the antenna and converts it into a digital signal that is sent to the USB port of the raspberry pi b+.

The raspberry pi $b+$ decodes the information uploaded by the SDR and converts it into a satellite image.

\section{RESUltS}

The implementation of the portable ground station has a total cost of 120 dollars, proving that it is economical compared to other ground stations, also because of its small size facilitates installation as seen in Fig. 9.

The obtained results with this system give us an average of 7 satellite images per day automatically. The system has demonstrated that it can emulate a ground station to get satellite images without presenting difficulties for the user in the operation of the equipment.

The obtained images have coverture of $1793 \mathrm{~km}$ x $3200 \mathrm{~km}$; this allows us to observe most of our territory both land and sea.

The image quality depends on how clear the sky is when the satellite passes through our location. When there are clouds, one receives distorted images like Fig. 10; however, when the sky is completely clear, the received image is sharp, as seen in Fig. 11. Also, images obtained at night have the same results.

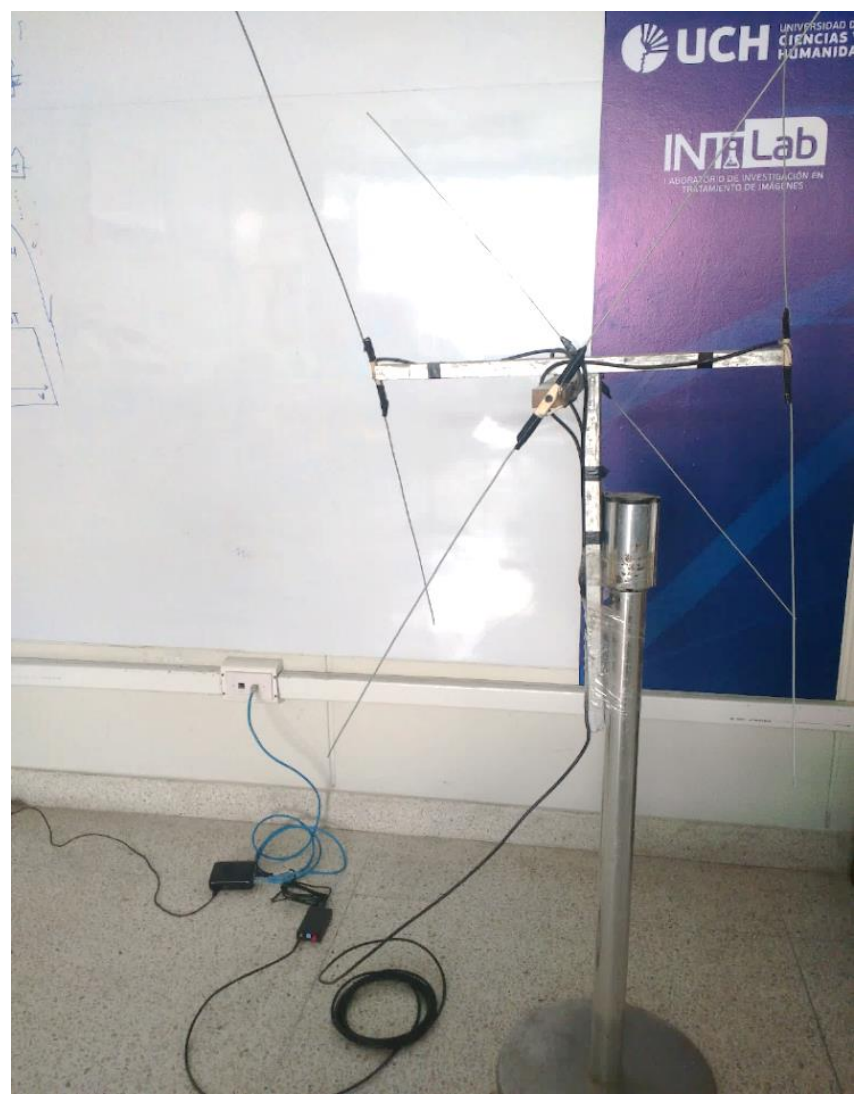

Fig. 9. Low-Cost and Portable Ground Station.

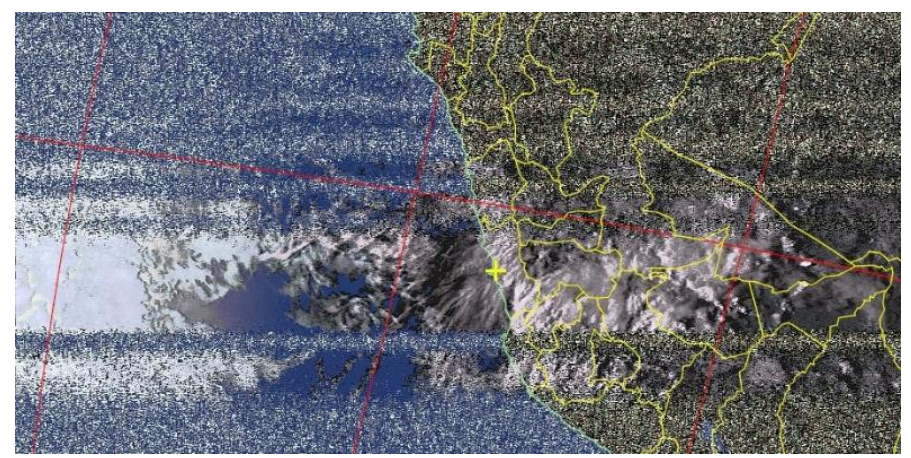

Fig. 10. Image with Cloudy Sky.

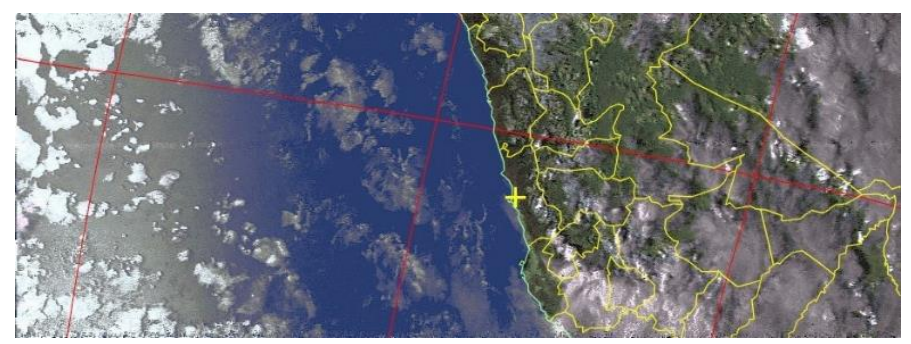

Fig. 11. Image with Clear Sky. 


\section{DISCUSSION}

In the present research, it was proposed as a primary objective to implement a low-cost and portable ground station system for automatically obtaining satellite images to motivate users in the study of the climatic patterns of its locality regarding the climate changes.

It is concluded that since this portable ground station is automatic, the user no longer has to wait for the satellite to pass through its location, thus facilitating the process of obtaining satellite images.

The portable ground station by its flexibility can be used to do image processing because the execution of applications responsible for the reception and decoding of satellite images work when passing satellites. This task could be used when no application is executed.

The idea is to continue with the research implemented by the system in colleges and universities to encourage students to study the analysis and forecasting of the climate in their region. Also, to prepare them for the future NOAA geostationary and polar orbit satellite systems.

The proposed low-cost and portable ground station could serve for education purpose in universities to do practices and laboratory experiments. It facilitates access to cheap laboratories for universities from developing countries.

As future work, one plans to add an orientation system for the reception of high-resolution images (HRPT), this will allow us to do image processing with high reliability.

\section{REFERENCES}

[1] CONIDA, "Suministro de imagenes satelitales del centro nacional de operaciones de imagenes satelitales," 2018.
[2] Roman-Gonzalez, Avid, and Natalia Indira Vargas-Cuentas. "Aerospace technology in peru." 66th International Astronautical Congress-IAC 2015. 2015.

[3] J. Gutiérrez Mendoza, O. Muñoz Valverde, and J. Flores Quispe, "Capacidad del satélite' perusat-1 en el desarrollo de inteligencia de imágenes' en apoyo a la 3a brigada de artillería del iii ejército de operaciones," 2018.

[4] J. F. Moreno and J. Melia, "A method for accurate geometric correction of noaa avhrr hrpt data," IEEE Transactions on Geoscience and Remote Sensing, vol. 31, no. 1, pp. 204-226, 1993.

[5] Velasco, César, and Christian Tipantuña. "Meteorological picture reception system using software defined radio (SDR)." 2017 IEEE Second Ecuador Technical Chapters Meeting (ETCM). IEEE, 2017.

[6] G. K. Davis, "History of the noaa satellite program," Journal of Applied Remote Sensing, vol. 1, no. 1, p. 012504, 2007.

[7] A. Roman-Gonzalez, and N. I. Vargas-Cuentas; "Analysis of Landslides in Peru Based on Satellite Images to Identify Danger Zones", 69th International Astronautical Congress - IAC 2018; Bremen - Alemania; Octubre 2018.

[8] C. W. Alvarez Busani, "Diseño y construccion de una antena double cross para recepcion de imagenes procedentes de satelites de orbita polar," 2012.

[9] C. Velasco and C. Tipantũna, "Meteorological picture reception system using software defined radio (sdr)," in 2017 IEEE Second Ecuador Technical Chapters Meeting (ETCM). IEEE, 2017, pp. 1-6.

[10] B. Farroñan, A. Ivan, and J. L. Zuñiga Peña, "Diseño e implementacion de un timbre inteligente basado en el internet de las cosas (iot) para fortalecer la seguridad contra robos en viviendas sociales."2019.

[11] W. Harrington, Learning Raspbian. Packt Publishing Ltd, 2015.

[12] M. Sruthi, M. Abirami, A. Manikkoth, R. Gandhiraj, and K. Soman, "Low cost digital transceiver design for software defined radio using rtl sdr," in 2013 international mutli-conference on automation, computing, communication, control and compressed sensing (iMac4s). IEEE, 2013, pp. 852-855.

[13] G. T. LASKOSKI and P. NOHAMA, "Um novo software livre para comunicação alternativa". 